\title{
Evolution Laws for Frozen Wall Formation under Conditions of Sudden Seepage
}

\author{
Song Zhang $\mathbb{D}^{1,2,3}$ Zurun Yue, ${ }^{1,2}$ Tiecheng Sun $\mathbb{D}^{1,2}$ Yufu Han, ${ }^{3}$ Wei Gao, ${ }^{3}$ Tianfei Hu, ${ }^{1,2}$ \\ and Yunxi Han ${ }^{1,2}$ \\ ${ }^{1}$ State Key Laboratory of Mechanical Behavior and System Safety of Traffic Engineering Structures, \\ Shijiazhuang Tiedao University, Shijiazhuang, Hebei 050043, China \\ ${ }^{2}$ School of Civil Engineering, Shijiazhuang Tiedao University, Shijiazhuang, Hebei 050043, China \\ ${ }^{3}$ Beijing China Coal Mine Engineering Co Ltd., Beijing 100013, China \\ Correspondence should be addressed to Tiecheng Sun; sferetg@163.com
}

Received 11 September 2020; Revised 29 October 2020; Accepted 24 November 2020; Published 7 December 2020

Academic Editor: Yu-Sheng Shen

Copyright (c) 2020 Song Zhang et al. This is an open access article distributed under the Creative Commons Attribution License, which permits unrestricted use, distribution, and reproduction in any medium, provided the original work is properly cited.

Sudden seepage is a special working condition affecting artificial ground freezing (AGF) in many projects which results in significant differences within the temperature field. In order to study the characteristics of frozen walls influenced by water flow, a series of model tests were carried out at different seepage velocities. The model test results show that a frozen wall will change from symmetrical to eccentric as the cooling energy absorption of the soil and the brine return temperature increase. In model tests, when the seepage velocity was $0 \sim 30 \mathrm{~m} / \mathrm{d}$, the frozen wall was partially destroyed. When the seepage velocity exceeded $30 \mathrm{~m} / \mathrm{d}$, the frozen wall was completely destroyed. This study examines the expansion rate of the upstream and downstream freezing fronts, and the distribution law of the freezing temperature field, the average temperature change under different seepage speeds, and the bearing capacity of the freezing wall are analyzed. Research on these factors suggests that a frozen wall has a certain level of resistance to sudden seepage. When the flow velocity is small, the freezing effect will be strengthened. With an increase in the flow velocity, the freezing effect will gradually weaken. Based on these conclusions, the current study points out targeted solutions that should be adopted in cases of sudden seepage in a project.

\section{Introduction}

The artificial ground freezing (AGF) method is a soil reinforcement method applied in underground engineering. Initially, the method was used for subway construction in Swansea, South Wales, in 1862 . Twenty years later, German mining engineering used the method in mine shaft construction [1]. Since then, AGF has also been applied for shaft sinking in coal mines [2]. In recent decades, the method has been widely used in the field of municipal engineering, especially in China.

AGF can enhance the strength of soils and reduce their permeability coefficients through the circulation of lowtemperature liquid nitrogen or brine. Groundwater flow is one of the biggest threats to the AGF method $[1,2]$. In response to this problem, a number of scholars have conducted research on the best ways to mitigate the effects of groundwater [3-11]. Scholars have conducted numerical calculations, model tests, and other research methods to analyze the influence of seepage. The effect of conditions of seepage on the evolution of the freezing temperature field $[3-5,11]$ and the optimization of plans for freezing pipe layouts or freezing front analytical solutions $[7,10]$ have been successfully analyzed. While these aforementioned studies mainly analyze the working conditions of natural seepage in the soil, they pay less attention to groundwater seepage resulting from human activities which is present during the freezing process [9]. In particular, there is no groundwater flow before freezing, but seepage occurs during the freezing process.

In this paper, seepage is referred to as sudden seepage. In most working conditions, the groundwater velocity of 
sudden seepage is basically constant. This study only discusses sudden seepage with a constant velocity, hereinafter referred to as sudden seepage. In the actual project, sudden seepage is mainly man-made. Various seepage causes are shown in Figure 1. Seepage 1 shows a freezing project for the shield arriving project. At the end of the active freezing period, the construction party began to dewater close to the project's frozen wall, causing sudden seepage (e.g., the first section of Zhengzhou Metro Line 2, China, and TBM arriving in a water diversion project in Hunan, China). Seepage 2 shows river water entering an annular space between a shield machine and the frozen wall along the soil fissure and causing sudden seepage in a TBM arriving project on Wuxi Metro Line 1, China [12]. Seepage 3 is caused by nearby engineering dewater during the freezing process of crossing passage $[13,14]$. Seepage 4 is the space between the freezing pipe and tunnel segments which does not block in crossing passage and causes water leakage long-term. In the end, it caused a sudden seepage around the frozen wall (freezing project of the cross passage in Foshan Metro Line 2, China). Upon investigation of these cases, four of them can be seen to have occurred at the stage where the frozen wall was formed. Some projects were completed, and some projects caused engineering accidents. For the TBM arriving project of Wuxi Metro 2, sudden seepage which lasted 2 3 days destroyed the frozen wall. The work-well was submerged about $8.0 \mathrm{~m}$. Therefore, sudden seepage cannot be ignored in an actual project as it might cause accidents or present safety risks.

\section{Model Test}

2.1. Similarity Laws. The effect of sudden seepage on the frozen wall is a problem characterized by the coupling of hydraulics and temperature. Therefore, a similarity law for the model test was determined before the model test was designed.

Based on dimensional analysis $[15,16]$, the temperature field governing equation in the dimensionless form is

$$
F\left(\frac{a t}{r^{2}}, \frac{L}{c T}, \frac{r_{0}}{r}, \frac{T_{d}}{T_{0}}, \frac{T_{c}}{T_{0}}\right)=0
$$

where $a$ is the thermal diffusivity of the soil, $t$ denotes the time, $r$ is the distance to the center of the freezing pipe, $L$ is the latent heat of the soil, $c$ is the specific heat of the soil, $T$ denotes the temperature, $r_{0}$ is the outer radius of the freezing pipe, $T_{d}$ is the freezing temperature of the soil, $T_{c}$ is the temperature of the freezing pipe, and $T_{0}$ is the initial temperature of the soil.

The governing equation of water flow is [17]

$$
\begin{aligned}
F\left(R_{e}, \frac{v t}{d}\right) & =0, \\
R_{e} & =\frac{\rho_{w} \nu d_{s}}{\mu_{w}},
\end{aligned}
$$

where $v$ is the seepage velocity, $d$ is the diameter of the freezing pipe, $R_{e}$ is the Reynolds number, $\rho_{w}$ is the density of water, $d_{s}$ is the equivalent pore diameter of the soil, and $\mu_{w}$ is the dynamic viscosity of water.

Because model test sand was taken from a project in Guangzhou, the physical parameters of the soil were consistent with the prototype. Thus, the similarity ratio of the soil thermophysical parameters is

$$
\frac{(C)_{p}}{(C)_{m}}=\frac{(L)_{p}}{(L)_{m}}=\frac{(T)_{p}}{(T)_{m}}=\frac{(\rho)_{p}}{(\rho)_{m}}=1,
$$

where subscripts $m$ and $p$ indicate the model and prototype, respectively.

The assumed geometric similarity ratio is $C_{l}$. The similarity ratio of temperature, time, and velocity of water can be expressed as

$$
\begin{aligned}
C_{T} \frac{(T)_{p}}{(T)_{m}} & =\frac{\left(T_{0}\right)_{p}}{\left(T_{0}\right)_{m}}=\frac{\left(T_{d}\right)_{p}}{\left(T_{d}\right)_{m}}=\frac{\left(T_{c}\right)_{p}}{\left(T_{c}\right)_{m}}=1, \\
C_{t} & =\frac{(t)_{p}}{(t)_{m}}=C_{l}^{2}, \\
C_{v} & =\frac{(v)_{p}}{(v)_{m}}=1 .
\end{aligned}
$$

This model test defined the geometric similarity ratio to be $1 / 5$. The key similarity ratios are listed in Table 1 .

2.2. Model Soils. The soil used in the model test was collected from a construction site in Guangzhou, China. Its physical parameters are shown in Table 2. In this table, the density, moisture content, and porosity of the soil were obtained from a geological exploration engineering report. The remaining thermophysical parameters were measured using the remoulded soil made using special samplemaking instruments. Soil was layered into a model tank, and a vibrating mechanism was then used to remould the soil and control compactness. Soil was collected using a ring knife for each layer $(100 \mathrm{~mm})$. Density and water content were made consistent with those of the undisturbed soil.

2.3. Model Test System. The model test apparatus consists of freezing, seepage, soil simulation, and measuring systems. Test system components are shown in Figure 2. In this figure, the blue dotted line represents the freezing system, while the green dotted line represents the seepage system, and the yellow dotted line represents the soil simulation system. Test equipment was installed inside a freezing station of a freezing project on Guangzhou Metro Line 11, as shown in Figure 3.

2.3.1. Freezing System. The freezing system was built over the refrigeration equipment of the freezing project. The project installed 38 YSLG16F refrigeration units $(125 \mathrm{~kW}), 5$ 


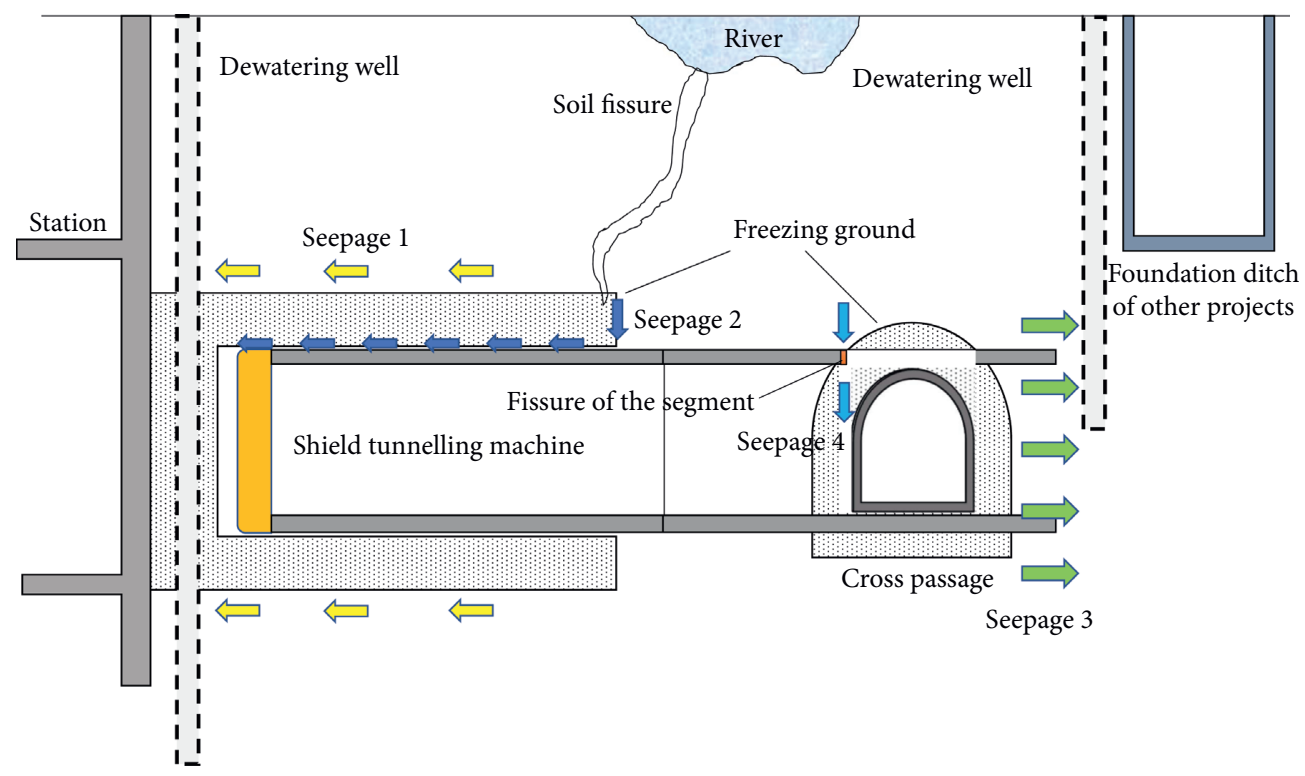

FIgURE 1: Types of sudden seepage.

TABLE 1: Similarity ratio of the model test.

\begin{tabular}{lccccc}
\hline Parameter & Geometric & Time & Temperature & Velocity of brine & Velocity of seepage \\
\hline Similarity ratio & $1 / 5$ & $1 / 25$ & 1 & $5 / 1$ & $5 / 1$ \\
\hline
\end{tabular}

TABle 2: Parameters of the soil.

\begin{tabular}{cccccc}
\hline Item & Density $\left(\mathrm{kg} \cdot \mathrm{m}^{3}\right)$ & Moisture content $(\%)$ & Porosity $(\%)$ & Thermal diffusivity $\left(\mathrm{m}^{2} / \mathrm{s}\right)$ & Freezing temperature $\left({ }^{\circ} \mathrm{C}\right)$ \\
\hline Data & $1.6 \times 10^{3}$ & 25.3 & 31 & 0.77 & -0.15 \\
\hline
\end{tabular}

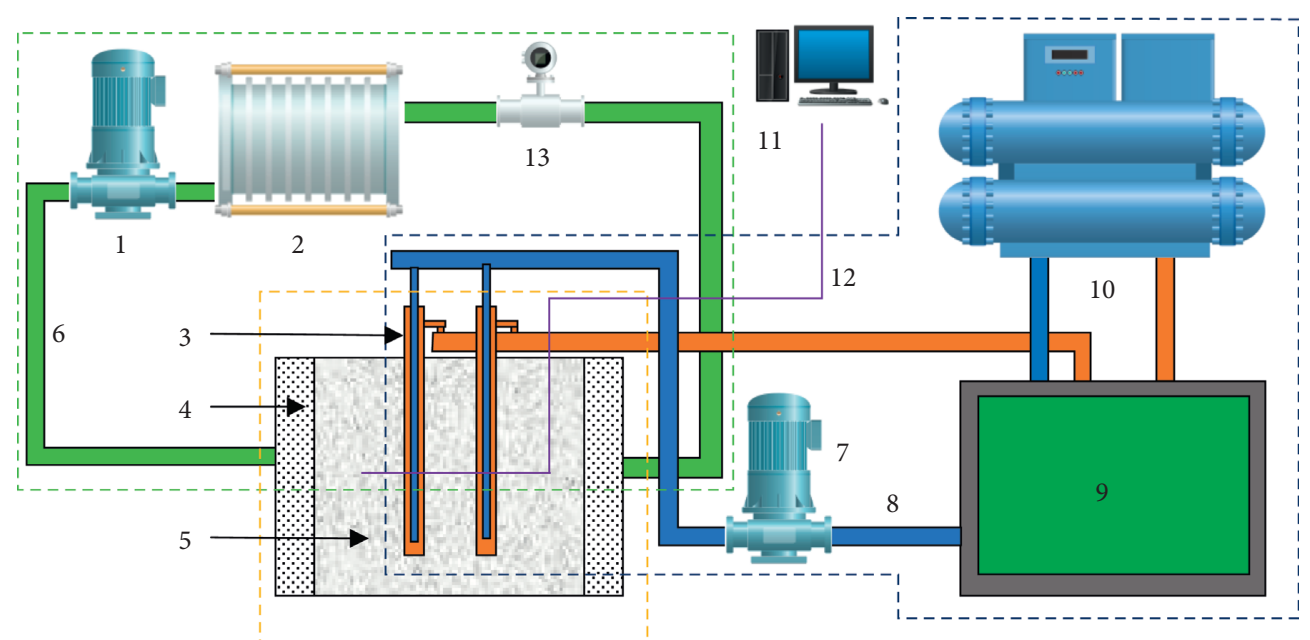

FIGURe 2: Model test system: 1, water circulation pump; 2, thermotank; 3, freezing pipe; 4, percolation filter layer; 5, soils; 6, water pipeline; 7, brine pump; 8 , brine pipeline; 9 , brine tank; 10, refrigerator; 11 , data collection terminal; 12 , temperature transmission cable; 13 , electromagnetic flowmeter and mechanical flowmeter.

brine pumps $(75 \mathrm{~kW})$, and 2 brine tanks $\left(10 \mathrm{~m}^{3}\right)$. Test brine was channelled out using a separate pipeline from the main pipeline. An electromagnetic flowmeter was installed to measure the brine flow rate.

In this model test, the prototype freezing pipe was $\Phi 108 \times 8 \mathrm{~mm}$, and the liquid supply pipe was $\Phi 48 \times 3 \mathrm{~mm}$.
Based on the similarity ratio, the freezing pipe is $\Phi 21.6 \times 2 \mathrm{~mm}$, and the liquid supply pipe is $\Phi 9.6 \times 1 \mathrm{~mm}$. There were 8 freezing pipes in 2 rows in the model test system arranged. Every freezing pipe had a length of $1.2 \mathrm{~m}$ (1.0 $\mathrm{m}$ in the soils). Freezing tubes were arranged in a plum blossom shape at a distance of $140.0 \mathrm{~mm}$ to simulate the 


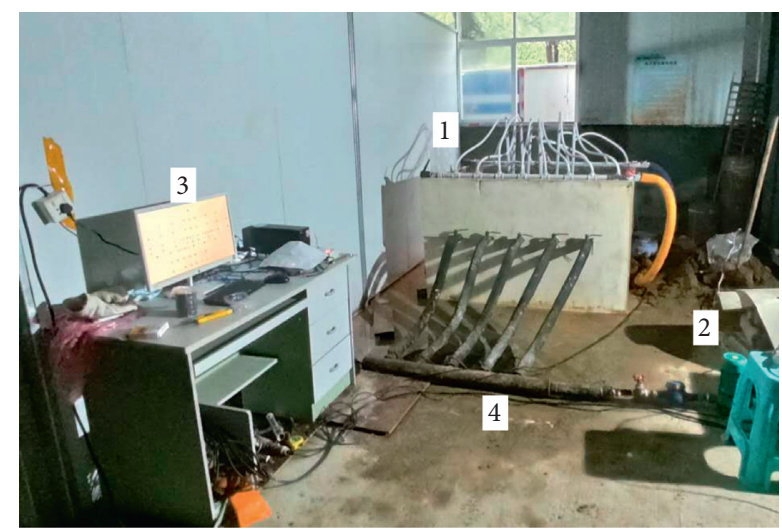

FIGURE 3: Scene photo of the model test system: 1, soil simulation system; 2, water pump; 3 , measuring system; 4 , water pipeline.

actual engineering conditions of the $5.0 \mathrm{~m}$ field freezing pipes at an interval of $0.7 \mathrm{~m}$. Each freezing pipe was equipped with an independent water inlet and return device to ensure that the brine inlet temperature was the same across the pipes.

2.3.2. Seepage System. The seepage system consists of a $400 \mathrm{~W}$ thermotank of water, an $800 \mathrm{~W}$ clean water inline pump, an electromagnetic flowmeter (DN $40 \mathrm{~mm}$ ), and mechanical flowmeter (DN40 mm). The two ends of each flowmeter were $20.0 \mathrm{~cm}$ long steel pipes to ensure the passage of water on either end of the flowmeter. A measuring cup was used for flow sampling in the open section near the thermotank.

2.3.3. Soil Simulation System. The model test tank was $1.5 \times 1.5 \times 1.2 \mathrm{~m}$ and made by an $8 \mathrm{~mm}$ steel plate. There were 5 water holes on the front and back of the tank. Each water hole's diameter was $50 \mathrm{~mm}$, and they were spaced $20 \mathrm{~cm}$ apart. From bottom to top, the model test tank fillings were a $10.0 \mathrm{~cm}$ clay layer, an $80.0 \mathrm{~cm}$ test fine sand layer, another $10.0 \mathrm{~cm}$ clay layer, and a $5.0 \mathrm{~cm}$ cement mortar top layer. In order to buffer water flow and ensure the uniformity of seepage, $20 \mathrm{~cm}$ of medium-coarse gravel and sand were added to both sides of the seepage flow in and out of the model tank. $5 \mathrm{~cm}$ clay layers were set on the other sides to prevent seepage at the steel-soil interface. Details of the model tank are shown in Figure 4. In order to ensure the uniformity of leakage flow, three 1.5 inch diameter flow test tubes were set $10 \mathrm{~cm}$ below the temperature measurement plane with a spacing of $40 \mathrm{~cm}$. The seepage system was run in a nonfreezing state, and the deviation of flow velocity in the 3 tubes was less than $5.6 \%$. Therefore, the seepage in the soils was considered uniform. In order to avoid heat exchange between the test soil and the outside air, a $5 \mathrm{~cm}$ insulation layer was placed around the model tank. A heat flux sensor was tied to the outside of the insulation layer. Throughout the test, the heat flux between the model tank and the outside air was less than $1 \mathrm{~W} / \mathrm{m}^{2}$. Through infrared temperature measurement in the test process, the temperature difference between the test box and the surrounding environment was found to be less than $1.0^{\circ} \mathrm{C}$, indicating a good heat preservation effect.

2.3.4. Measuring System. In the model test, the DS18b20 sensor was chosen as a measuring point. The accuracy of the sensor was $\pm 0.06^{\circ} \mathrm{C}$. All sensors used the CHL-RTU-V1 single-bus acquisition module to collect and transmit to an RS485/USB isolation converter before transmitting to a PC configuration system. The system connection is shown in Figure 5. All sensors were calibrated at four points of -20 , $-10,0$, and $20^{\circ} \mathrm{C}$ before embedding. The calibration equipment was a JM222 handheld thermometer, as shown in Figure 6. The buried depth of temperature measurement points and the division of temperature measurement areas are shown in Figure 7. In the figure, area I is the upstream area, area II is the frozen central core area, area III is the single-row freezing area, and area IV is the downstream area. The location of T26 is the origin of the coordinates. $X$ and $Y$ coordinates are also shown.

2.4. Test Arrangement. The model test was divided into 5 sections listed in Table 3. In tests 2 to 5, seepage began after T18's temperature dropped to $-4.0 \sim-5.0^{\circ} \mathrm{C}$. At that time, the frozen wall had formed, and the corresponding prototype was actively frozen in the late stages of the active freezing period. The frozen wall was approximated to meet design requirements. In this way, the working conditions of a formed frozen wall facing sudden seepage during the late stages of the active freezing period were simulated.

\section{Results}

3.1. Refrigeration Efficiency during the Freezing Period. The temperature of the return pipeline's outer surface during the active freezing period is shown in Figure 8. Data shown in this figure were tested using a DS18b20 temperature sensor attached to the return pipeline and covered with a thermal insulation layer. In all the tests, the inlet brine temperature was maintained at $-28^{\circ} \mathrm{C}$. In test 1 , the return temperature was stable, while the return temperature rose obviously in the other 4 tests. The temperature increase in tests $2 \sim 5$ occurred after seepage started $40 \sim 80$ minutes in the test. The soil absorption cooling energy capacity was measured as

$$
Q=q \cdot c \cdot \rho_{b} \cdot \Delta t,
$$

where $Q$ is the absorption cooling energy, $\mathrm{kJ} / \mathrm{h} ; q$ is the flux of brine, $\mathrm{m}^{3} / \mathrm{h} ; \Delta t$ is the temperature difference, ${ }^{\circ} \mathrm{C}$, of brine between the inlet and the outlet; and $\rho_{b}$ is the density of brine, $\mathrm{kg} / \mathrm{m}^{3}$.

In tests $1 \sim 5$, the brine inlet temperature and the length of the freezing pipe were the same. In Figure 8, soil absorption cooling capacity can be seen to have a linear relationship with the temperature. This indicates that, after seepage occurs, soil absorption cooling capacity will increase significantly, and brine return temperature will increase rapidly. 


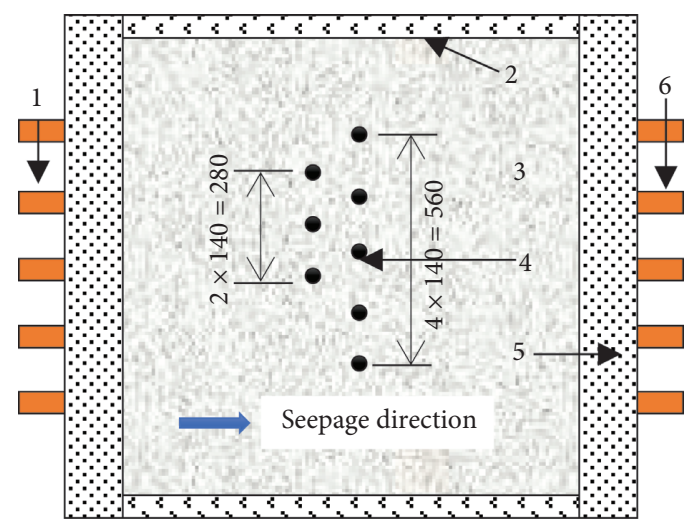

(a)

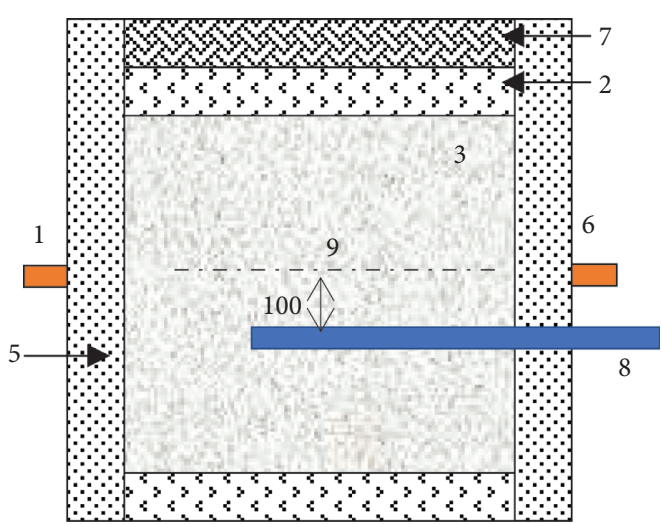

(b)

Figure 4: Design of the model tank. (a) Top view of the model tank. (b) Side view of the model tank. 1, seepage entrance; 2, clay layer; 3, soils; 4 , freezing pipe; 5 , percolation filter layer; 6 , export of seepage; 7 , cement mortar; 8 , seepage velocity tube; 9 , temperature measurement plane.

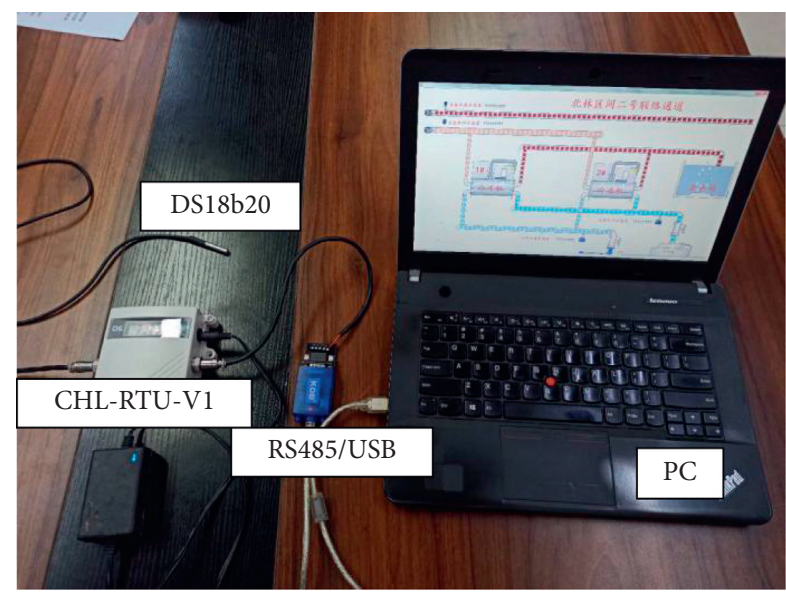

Figure 5: Schematic diagram of the temperature test system.

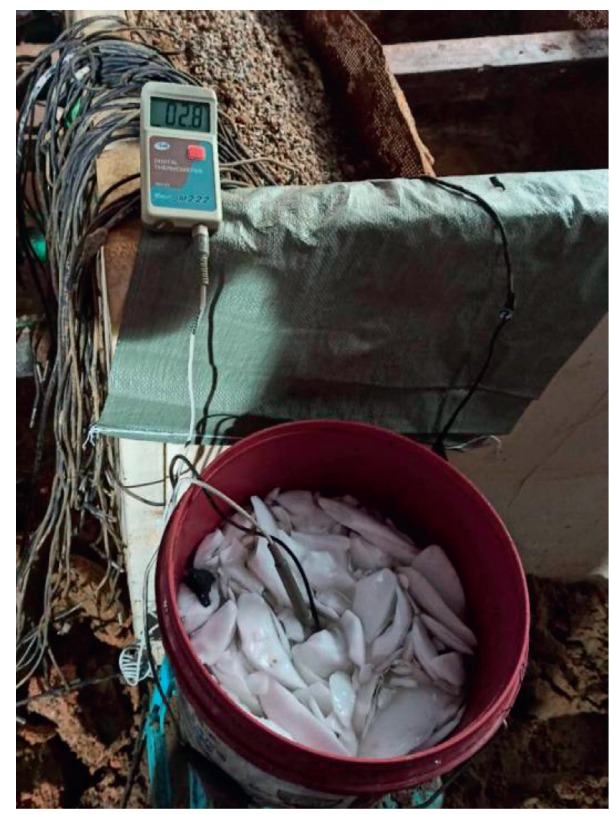

FIgURE 6: Sensor temperature calibration.
3.2. The Evolution Law of the Temperature Field. In the model test, every test took more than 600 minutes. The sudden seepage starting time was roughly between 170 and $190 \mathrm{~min}$. Figure 9 shows the temperature field for tests 1, 3, and 5 at the 100th, 300th, and 600th minute. In this figure, the black dotted line is the reference line of the upstream and downstream frozen front. As shown in Figure 9, the frozen wall for each test was uniform before seepage $(t=100 \mathrm{~min})$. Though the upstream frozen wall was still uniform, test 3's downstream frozen wall was thicker than tests 1 and 5 at $t=300 \mathrm{~min}$. At the end of the tests $(t=600 \mathrm{~min})$, the upstream frozen wall in test 1 was thicker than that of tests 3 and 5, while the downstream frozen wall in test 3 was obviously thicker than tests 1 and 5 .

At $t=300 \mathrm{~min}$ during the active freezing period, the unfrozen zone in area III was $48 \mathrm{~mm}$ in test $1,45 \mathrm{~mm}$ in test 3 , and $64 \mathrm{~mm}$ in test 5 . At $t=600 \mathrm{~min}$ during the active freezing period, there was no unfrozen zone in tests 1 and 3 . However, the thickness of the unfrozen zone in test 5 was $13 \mathrm{~mm}$.

Above all, the results of all the tests show that when the velocity of seepage is low, it does not affect the integrity of the frozen wall. With the increase of seepage velocity, this promoting effect will gradually disappear. The double-row pipe layout obviously outperformed the single-row pipe layout in terms of seepage conditions. It can quickly complete the freezing wall closure and maintain the expansion of the frozen wall under a certain seepage velocity.

Figure 10 is the time history curve of the main temperature measurement points for each test. As shown in the figure, upstream area I demonstrated a significant temperature drop under the influence of seepage. Area II showed a certain degree of freezing effect enhancement. The enhancement effect of test 2 was the most obvious. Area III showed similarity to area I in that the temperature drop slowed. Area IV showed significant acceleration in the temperature drop.

Comparing the temperature of each main measuring point, the temperature drop degree of T34 was about $6 \sim 10^{\circ} \mathrm{C}$ 


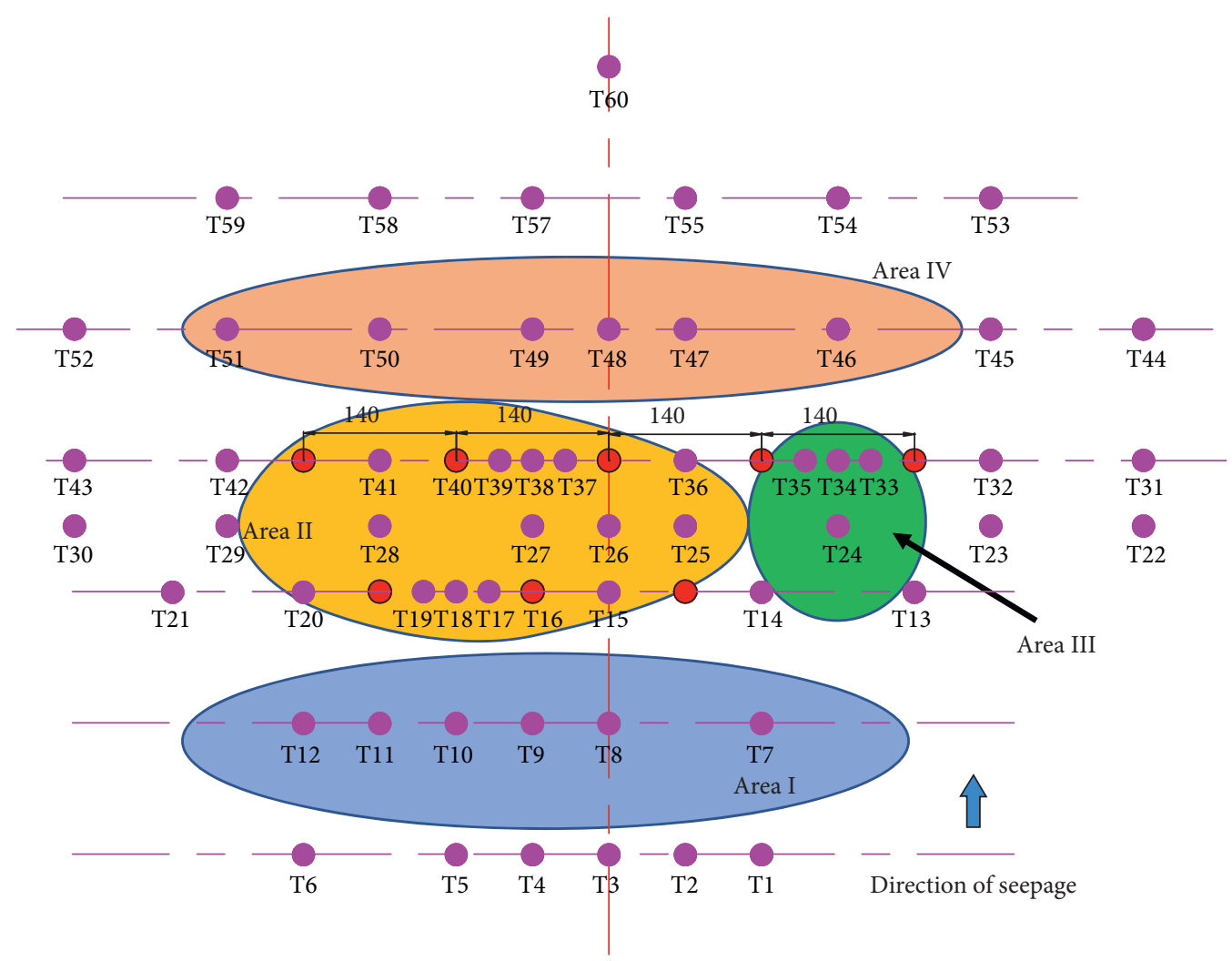

Figure 7: Layout of temperature measurement points.

TABLE 3: Velocity of the model test.

\begin{tabular}{lc}
\hline No. & Velocity of seepage $(\mathrm{m} / \mathrm{d})$ \\
\hline 1 & 0 \\
2 & 8 \\
3 & 16 \\
4 & 20 \\
5 & 30 \\
\hline
\end{tabular}

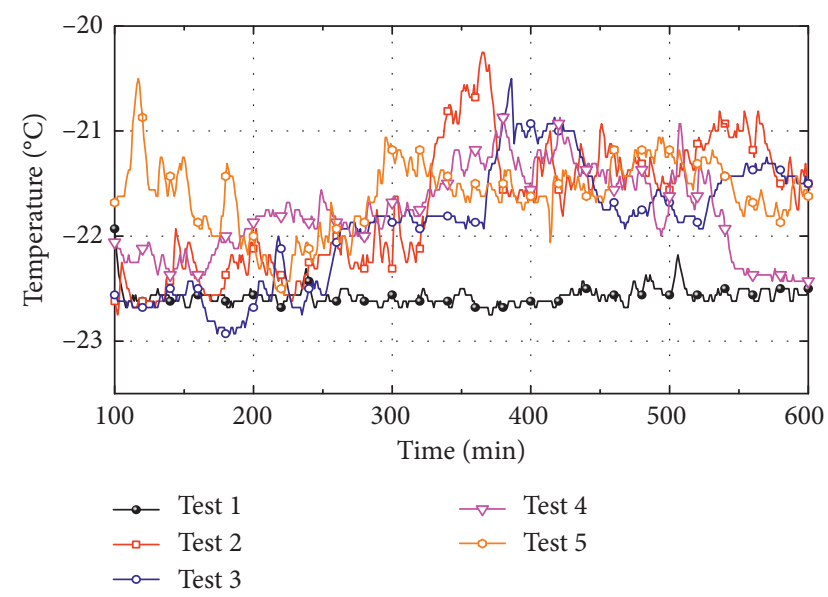

FIGURE 8: Temperature of the return pipeline's outer surface.

(from seepage start to $600 \mathrm{~min}$ ), and T26 was about $12 \sim 14^{\circ} \mathrm{C}$. This means that the double-rowed freezing pipes had a better cooling effect.
Figure 11 shows data extracted from each measuring point of the $X=0 \mathrm{~mm}$ section of tests $2 \sim 4$, used to obtain the temperature distribution curve along the seepage direction. The cyan column is the projection position of the freezing pipes, and the black dashed line is the temperature distribution curve at the same time as the purple solid line under no seepage conditions.

Based on these data, the negative effects of seepage seem to exist mainly in area I, while the promotion effect is mainly concentrated in areas II and IV. When the flow velocity reaches $30 \mathrm{~m} / \mathrm{d}$, the freezing effect of each area was found to be weaker than or equal to the nonseepage test.

\section{Discussion}

According to the test results, under certain seepage velocity conditions, the frozen wall exhibits a state of weakening in the upstream and strengthening in the middle and downstream. However, the freezing curtain should be regarded as a whole in order to evaluate its carrying capacity. Therefore, it is necessary to further analyze the freezing effect through the macroindicators of freezing curtain thickness and average temperature.

4.1. The Thickness and Expansion Rate of the Frozen Wall. As the result shows, the soil between the two rows of freezing pipes is in a frozen state, so the thickness of the freezing wall mainly depends on the position of the upstream and downstream freezing fronts. 

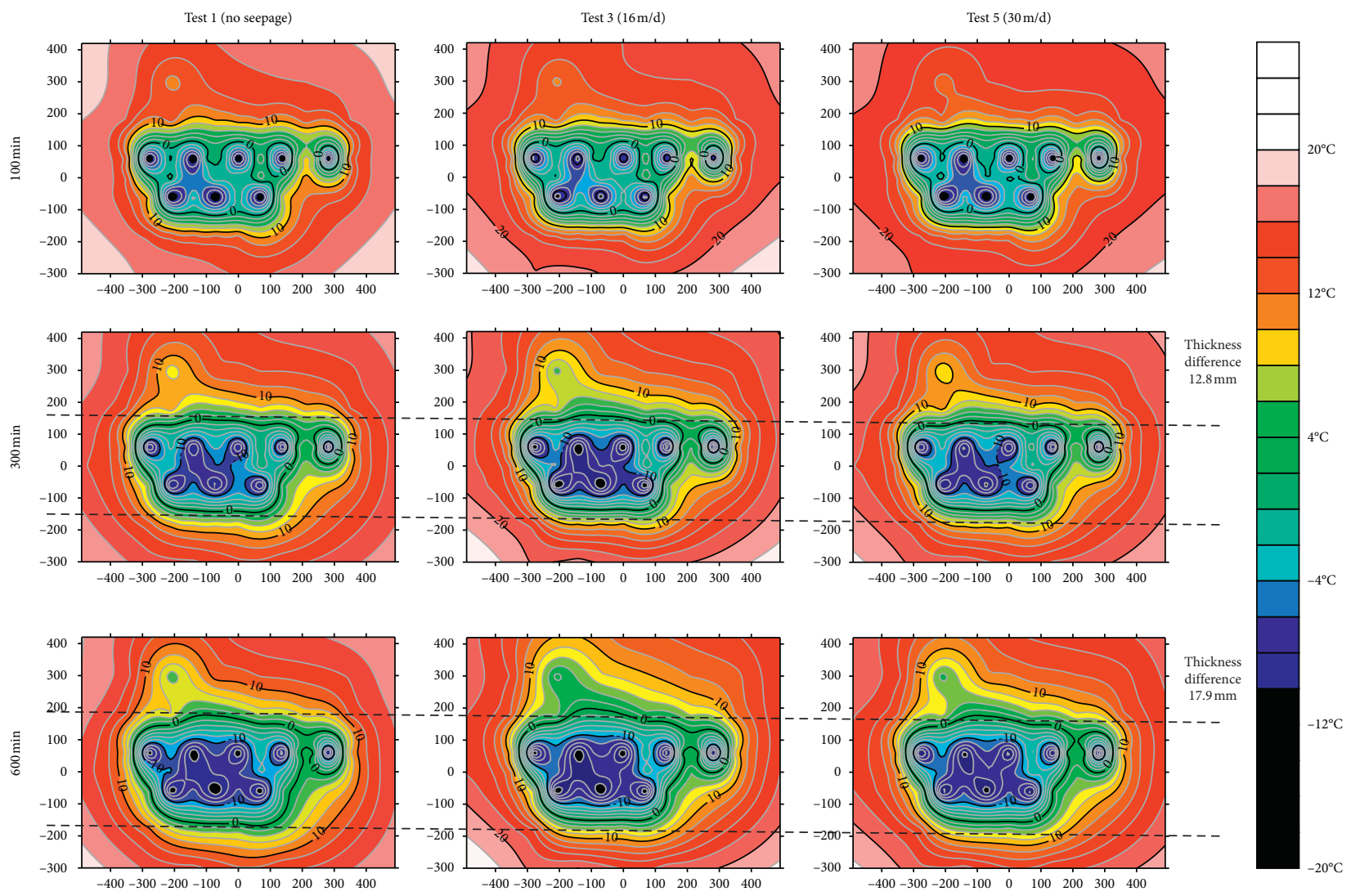

FIgure 9: Temperature field at different times.
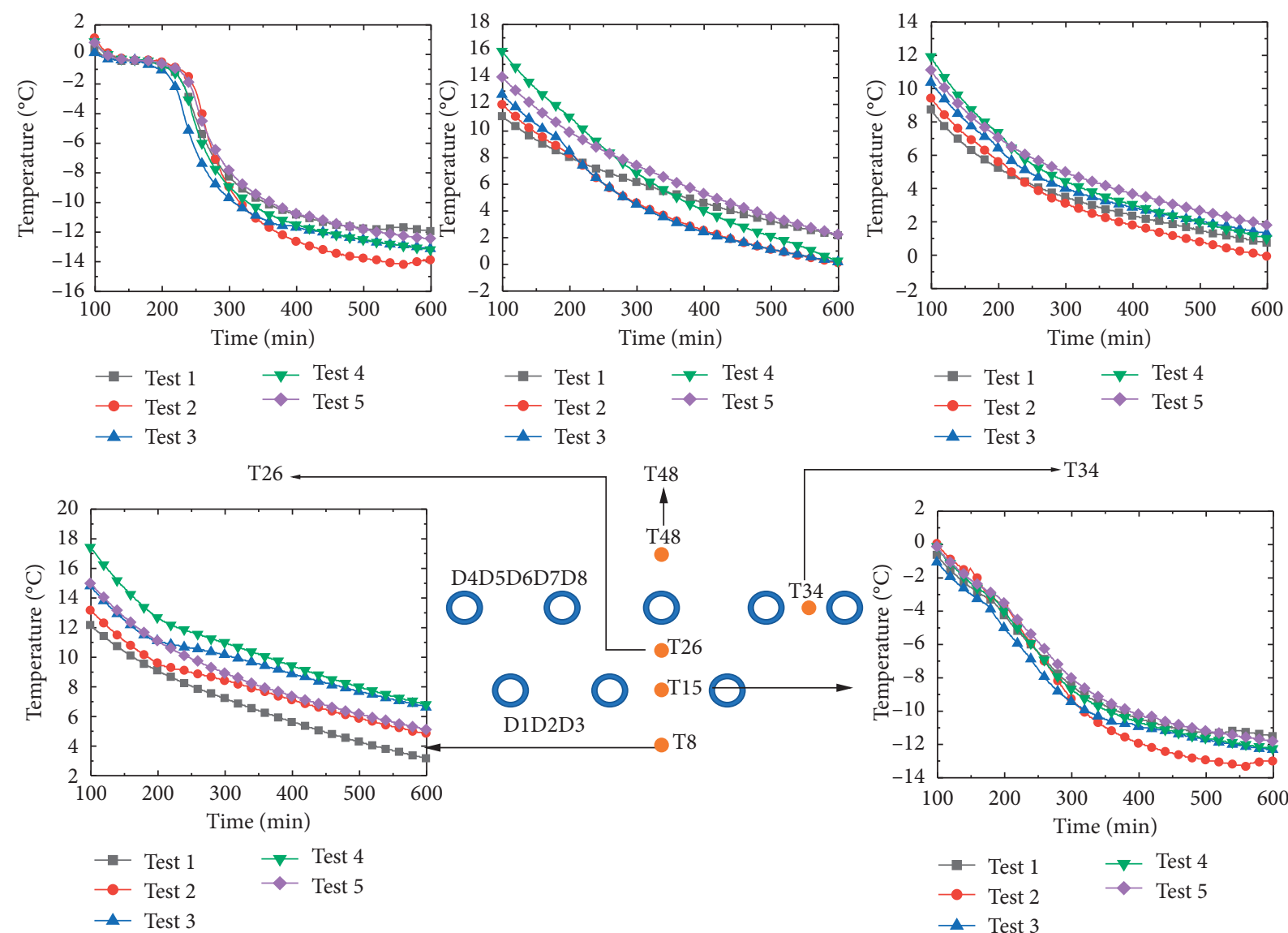


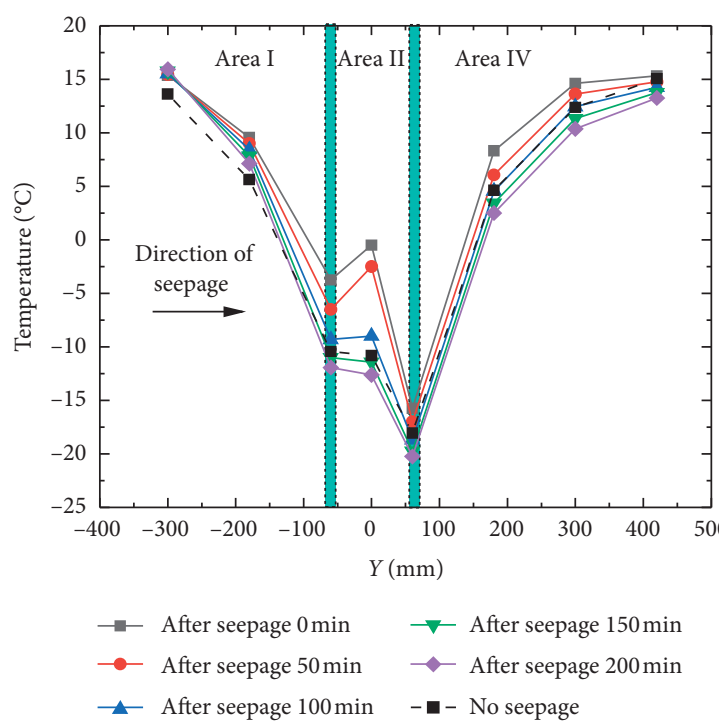

(a)

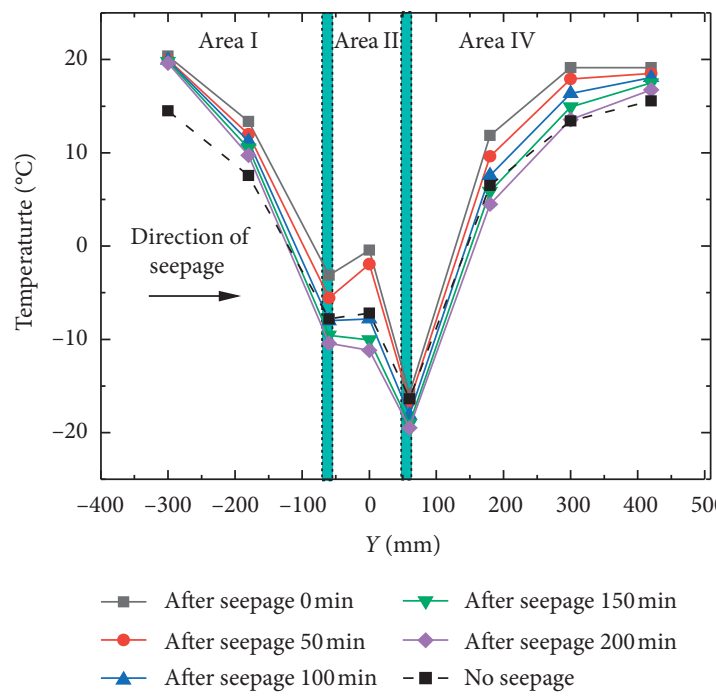

(c)

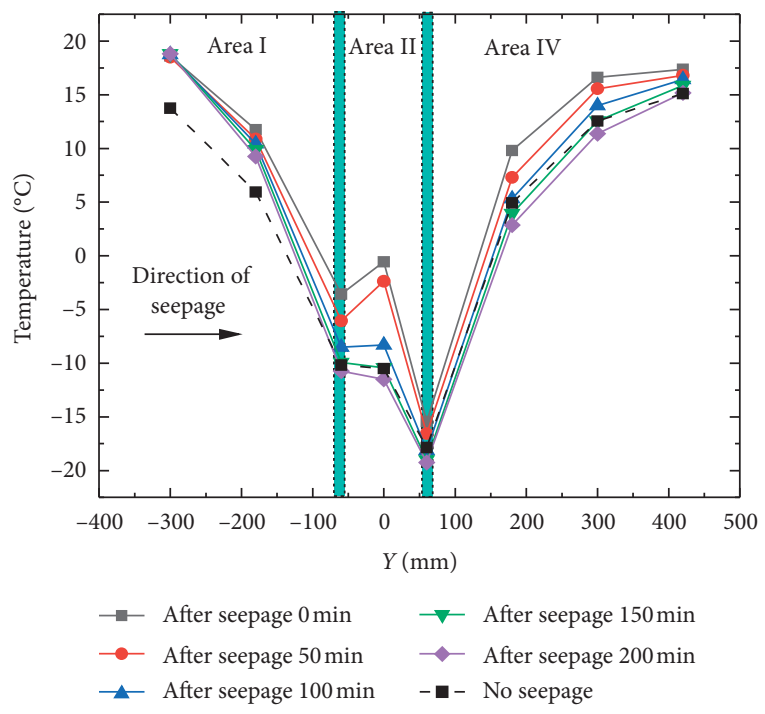

(b)

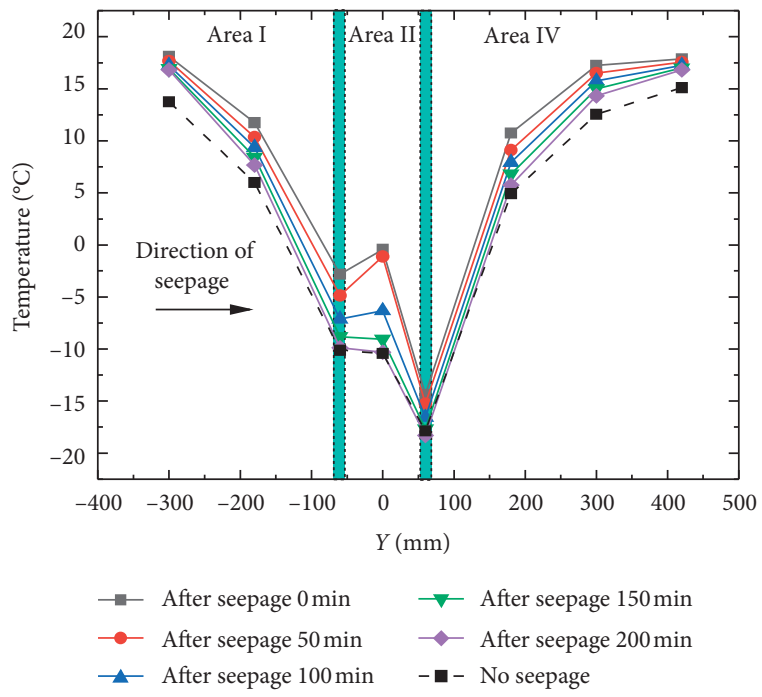

(d)

Figure 11: Temperature distribution in the $X=0 \mathrm{~mm}$ section. (a) Test 2. (b) Test 3. (c) Test 4. (d) Test 5.

The upstream freezing front position was calculated using T9 and D2 temperature data. The downstream freezing front position was calculated using data from T48 and D6. The calculation formula uses Bahorkin's analytical solution [2]:

$$
\begin{aligned}
m_{1}(x, y) & =\frac{1}{2} \ln \left[2\left(\operatorname{ch} \frac{2 \pi}{l} y-\cos \frac{2 \pi}{l} x\right)\right], \\
\xi & =\frac{l}{\pi} \frac{t(x, y) \ln \left(l / 2 \pi r_{0}\right)+t_{C T} m_{1}(x, y)}{t_{C T}-t(x, y)},
\end{aligned}
$$

where $x$ and $y$ are the location of the local coordinate system where the temperature measurement point is used in the calculation. The coordinate system takes the center of the freezing pipe closest to the temperature measurement point as the coordinate origin. The freezing axis is the $x$-direction, and the unit is $m . l$ is the freezing hole spacing in meters, $t(x, y)$ is the temperature at the temperature measurement point in ${ }^{\circ} \mathrm{C}$, and $t_{c t}$ is the out surface temperature of the freezing pipe in ${ }^{\circ} \mathrm{C}$.

Since Bahorkin's solution is a calculation scheme, it can be used after closure of the freezing curtain. The thickness of the frozen wall was only calculated from the 100th to 700th minute of the test. The results are shown in Figure 12. As shown in the figure, in the states of no flow velocity and $8 \mathrm{~m} /$ $\mathrm{d}$ flow velocity, the thickness of the upstream and downstream frozen walls both increased logarithmically, and the growth pattern was basically the same. When the flow velocity reached $16 \mathrm{~m} / \mathrm{d}$, the growth trend of the upstream and downstream frozen wall thickness developed and differentiated. The upstream frozen wall's growth slowed down slightly, while the downstream frozen wall's thickness increased rapidly. When the flow velocity reached $20 \mathrm{~m} / \mathrm{d}$, the growth effect of the downstream freezing wall began to 


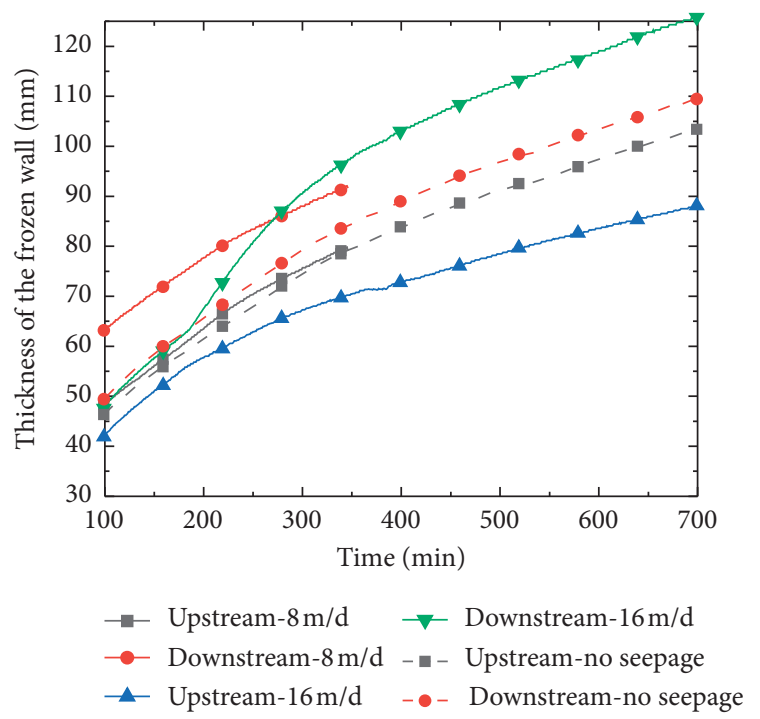

(a)

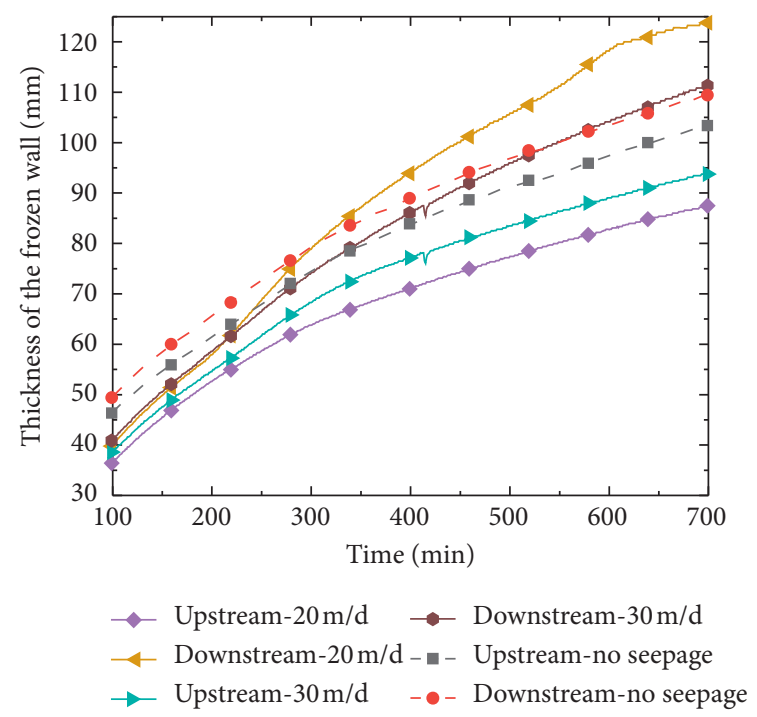

(b)

Figure 12: Thickness of the frozen wall in upstream and downstream. (a) Tests 1, 2, and 3. (b) Tests 1, 4, and 5.

weaken, but that of the upstream wall was basically the same. When the flow velocity reached $30 \mathrm{~m} / \mathrm{d}$, the thickness increase effect of the downstream frozen wall caused by seepage had basically disappeared, while that of the upstream remained basically the same.

Derivation of the position curve for the freezing front in each test with respect to time and the expansion rate of the frozen curtain in the upstream and downstream directions are shown in Figure 13. After seepage occurred, the expansion rate of the upstream freezing wall decreased, but the decrease was not large, and the difference was more or less negligible in the later stages of the test. The expansion rate of the downstream frozen wall demonstrated a rapid growth stage (cyan in Figure 13) under seepage rate conditions of $16 \mathrm{~m} / \mathrm{d}$ and $20 \mathrm{~m} / \mathrm{d}$. The peak appearance time of the growth stage slowed down with the increase of seepage velocity. Following the growth stage, the expansion rate under seepage was the same as it was under nonseepage conditions. This indicates seepage from upstream to downstream will transfer a lot of cooling energy. Thus, a rapid change stage is formed in the period of time after seepage. After this stage, the expansion rate of the frozen wall will slow down to match that of the wall when no seepage conditions are present.

4.2. The Average Temperature of the Frozen Wall. In order to analyze the distribution of the temperature field under different seepage conditions, the freezing wall temperature is divided into four temperature ranges: $0 \sim-5^{\circ} \mathrm{C},-5 \sim-10^{\circ} \mathrm{C}$, $-10 \sim-15^{\circ} \mathrm{C}$, and below $-15^{\circ} \mathrm{C}$. The area of each temperature range was then calculated under different conditions. The area calculation method was used to refine measurement point data to $1000 \times 560$ by the kriging method [18]. These refined data were then used to draw an isotherm map to calculate the area of each temperature interval. The calculation results are shown in Figure 14. As shown in the figure, when the flow rate was low $(8 \mathrm{~m} / \mathrm{d})$, the area of $0 \sim-5^{\circ} \mathrm{C}$ remained basically unchanged, the area of below $-15^{\circ} \mathrm{C}$ increased rapidly, and the area of $-5 \sim-15^{\circ} \mathrm{C}$ weakened. Therefore, the whole frozen wall increased to a certain extent. When the flow rate reached the range of $16 \sim 20 \mathrm{~m} / \mathrm{d}$, the area within $0 \sim-5^{\circ} \mathrm{C}$ and the area below $-15^{\circ} \mathrm{C}$ obviously decreased, while the area within the $-5 \sim-15^{\circ} \mathrm{C}$ temperature range decreased slightly. When the flow rate reached $30 \mathrm{~m} / \mathrm{d}$, the area within the $0 \sim-5^{\circ} \mathrm{C}$ temperature range continued to decrease slightly, while the area within the $-5 \sim-15^{\circ} \mathrm{C}$ range rose slightly, and the area below $-15^{\circ} \mathrm{C}$ dropped rapidly.

Since the temperature points obtained by the kriging interpolation method were evenly distributed, the average temperature of the freezing wall was obtained by calculating the average temperature of all the points lower than $0^{\circ} \mathrm{C}$. The average temperature and the area of the frozen wall are shown in Figure 15. Assuming that the area of the frozen wall under nonseepage conditions was $100 \%$, the area of the frozen wall under different conditions for tests $1-5$ was calculated to be $110.4 \%, 101.7 \%, 101.5 \%$, and $97.1 \%$, respectively. These data indicate how low-velocity seepage can promote frozen wall expansion.

4.3. Frozen Wall Bearing Capacity under Seepage. The frozen wall was defined as a line elastomer in accordance with the construction design code in China [19]. The bending modulus EI is generally used to evaluate its bearing capacity. It can be calculated as

$$
\mathrm{EI}=a \cdot \bar{T} \cdot \frac{b h^{3}}{12}
$$

where $a$ is the empirical coefficient, which is the ratio of elastic modulus to average temperature, mainly related to parameters such as soil quality, moisture content, and porosity; $\bar{T}$ is the average temperature of the frozen wall in ${ }^{\circ} \mathrm{C} ; b$ 


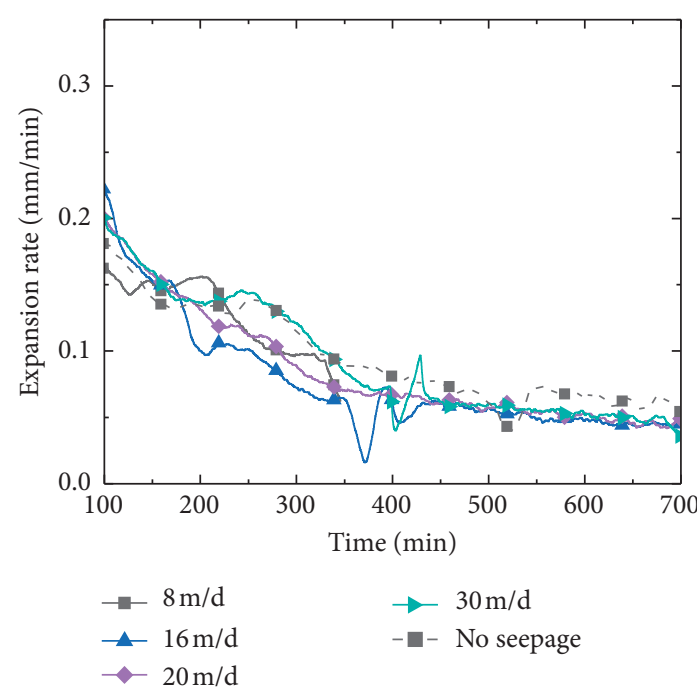

(a)

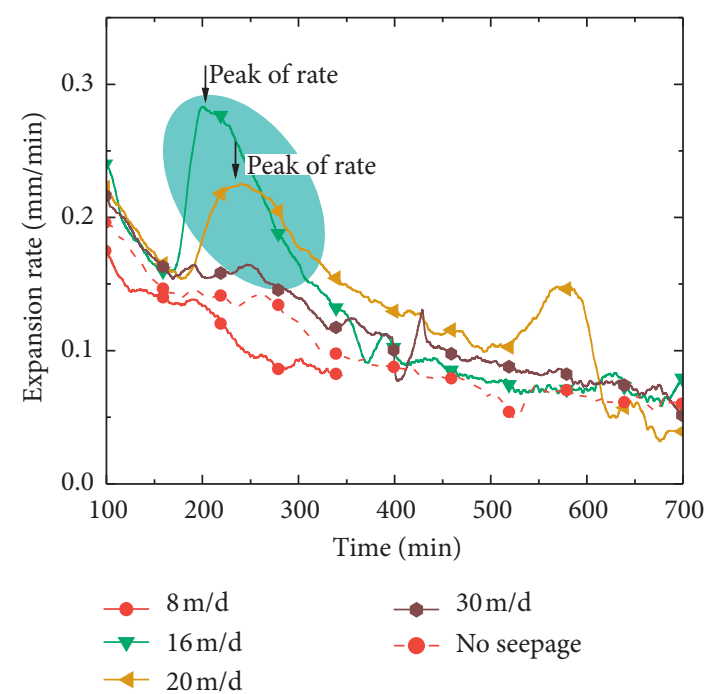

(b)

Figure 13: Expansion of the frozen wall in (a) upstream and (b) downstream.

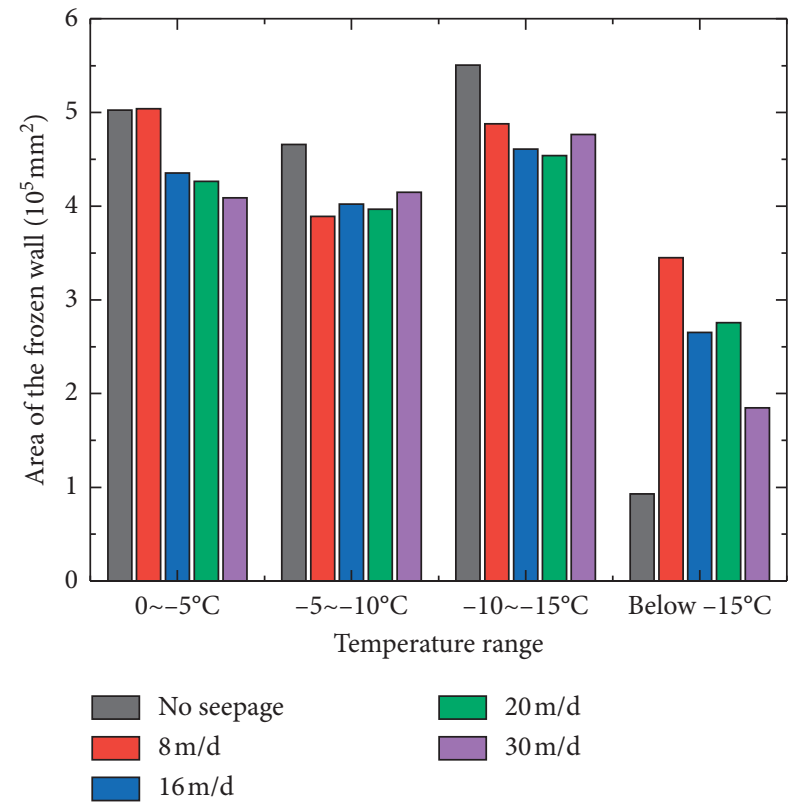

FIGURE 14: Area of the temperature stage.

is the width of the frozen wall, generally taken to be $1.0 \mathrm{~m}$ in conventional calculations; and $h$ is the thickness of the frozen wall in meters. The positional relationship of each parameter is shown in Figure 16.

Because the elastic modulus of the frozen soil has a linear relationship with the average temperature [20], $\alpha$ is a fixed value, and $b$ is also taken as a fixed value in the calculation. The damage evaluation coefficient of the frozen wall under the action of the flow field at any time can be written as

$$
\eta=\frac{\left.\mathrm{EI}\right|_{\text {seepage }}}{\left.\mathrm{EI}\right|_{\text {no seepage }}}=\frac{\left.\bar{T} \mathrm{~h}^{3}\right|_{\text {seepage }}}{\left.\bar{T} \mathrm{~h}^{3}\right|_{\text {no seepage }}},
$$

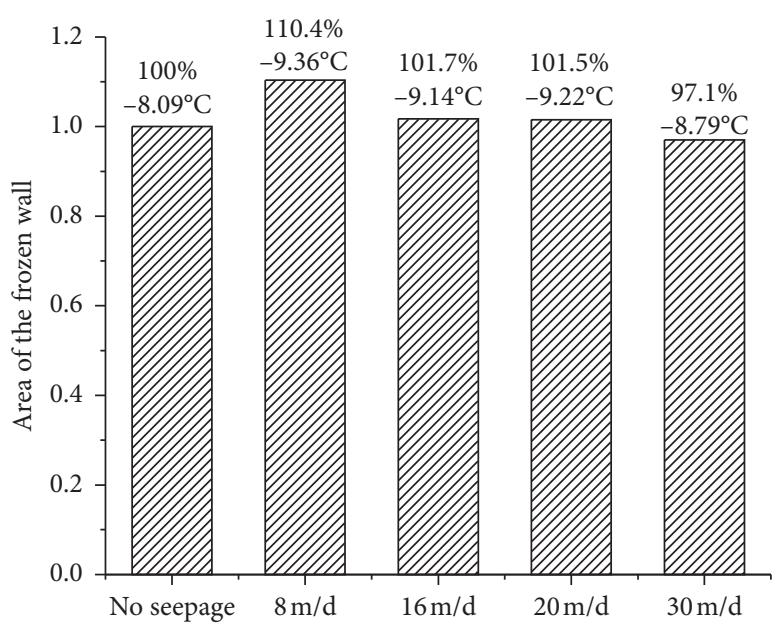

Figure 15: Average temperature in different tests.

where $\eta$ is the freezing damage coefficient, and its unit is 1 . When the unit is less than 1, the soil is in a damage stage. When it is greater than 1 , the soil is in a strengthening state.

The damage coefficient of the bearing capacity at different seepage rates during active freezing at $t=400 \mathrm{~min}$, $t=500 \mathrm{~min}$, and $t=600 \mathrm{~min}$ was calculated. The thickness of the frozen wall was selected as the section thickness of $x=0 \mathrm{~mm}$. The calculation results are listed in Table 4 . The damage coefficient curve is plotted in Figure 17.

When the flow rate is low, the seepage has a certain enhancement effect on the bearing capacity of the frozen wall, but with the increase of the seepage velocity, the enhancement effect gradually weakens and enters the stage of damage. Under similar seepage rate conditions, the damage evaluation coefficient showed an increasing trend with the extension of freezing time, indicating that the damage caused by the flow field to the frozen wall was most obvious in the early stages of freezing and that, with the 


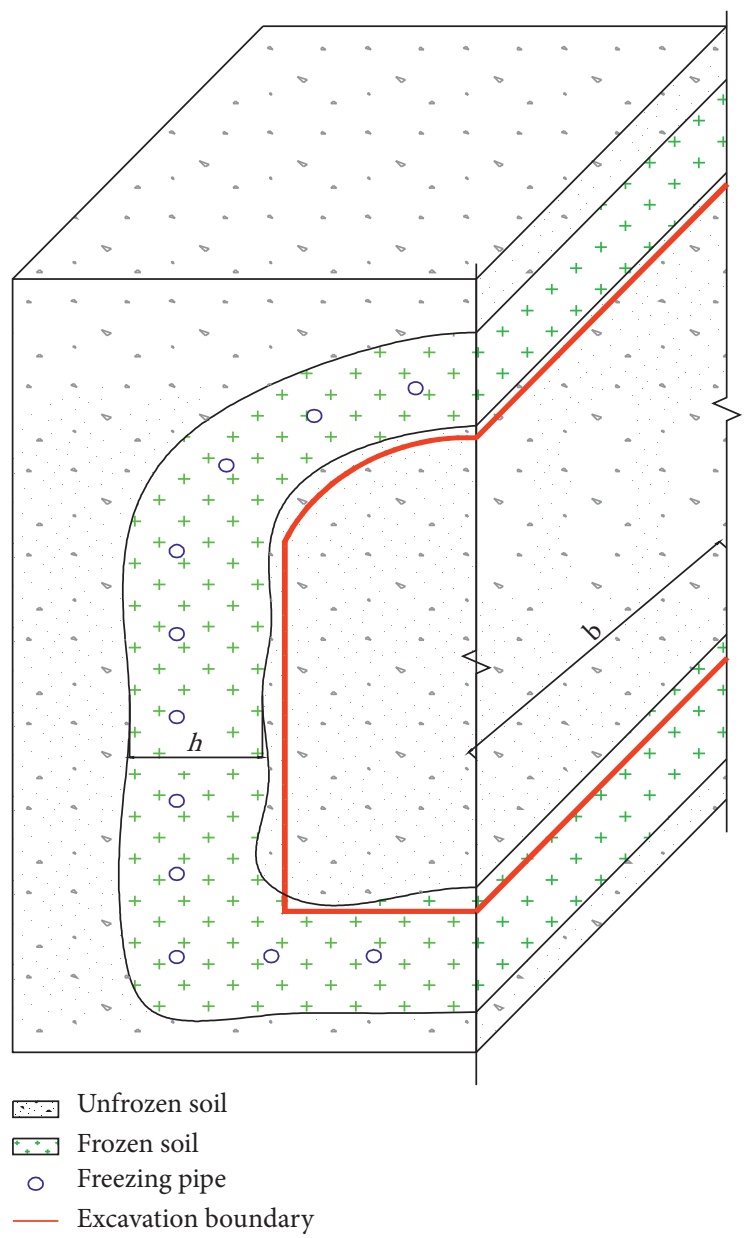

FiguRe 16: Schematic diagram of bending modulus calculation parameters.

TABle 4: Damage coefficient.

\begin{tabular}{|c|c|c|c|c|c|c|}
\hline Seepage velocity $(\mathrm{m} / \mathrm{d})$ & 0 & 8 & 16 & 20 & 30 & Time (min) \\
\hline$h(\mathrm{~mm})$ & 295.89 & 295.89 & 286 & 276.2 & 276.2 & \multirow{4}{*}{400} \\
\hline$T\left({ }^{\circ} \mathrm{C}\right)$ & -8.51 & -10 & -9.4 & -8.8 & -8.8 & \\
\hline EI & $2.20 \times 10^{8}$ & $2.59 \times 10^{8}$ & $2.2 \times 10^{8}$ & $1.85 \times 10^{8}$ & $1.85 \times 10^{8}$ & \\
\hline$\eta$ & 1 & 1.175088 & 0.997483 & 0.841072 & 0.841072 & \\
\hline$h(\mathrm{~mm})$ & 295.89 & 315.6 & 305.8 & 295.9 & 286 & \multirow{4}{*}{500} \\
\hline$T\left({ }^{\circ} \mathrm{C}\right)$ & -9.4 & -10.4 & -9.6 & -9.8 & -9.5 & \\
\hline EI & $2.43 \times 10^{8}$ & $3.27 \times 10^{8}$ & $2.75 \times 10^{8}$ & $2.54 \times 10^{8}$ & $2.22 \mathrm{E} \times 10^{8}$ & \\
\hline$\eta$ & 1 & 1.342535 & 1.127366 & 1.042659 & 0.912647 & \\
\hline$h(\mathrm{~mm})$ & 325 & 337 & 328 & 326 & 319 & \multirow{4}{*}{600} \\
\hline$T\left({ }^{\circ} \mathrm{C}\right)$ & -9.17 & -10.72 & -10.3 & -10.3 & -9.59 & \\
\hline EI & $3.14 \times 10^{8}$ & $4.1 \times 10^{8}$ & $3.63 \times 10^{8}$ & $3.57 \times 10^{8}$ & $3.11 \mathrm{E} 10^{8}$ & \\
\hline$\eta$ & 1 & 1.303362 & 1.154621 & 1.133628 & 0.988943 & \\
\hline
\end{tabular}

extension of freezing time, such damage could be repaired to a certain extent.

All in all, it can be seen that low-rate seepage can promote the bearing capacity of the frozen wall. In the actual project, if sudden seepage occurs, it must take a series of measures to reduce or remove the seepage such as grouting, reducing the temperature of brine, or increasing the brine flow. However, such treatments would greatly increase the cost of a project. Therefore, identifying a critical flow rate $(30 \mathrm{~m} / \mathrm{d}$ in this test) through model testing to distinguish 


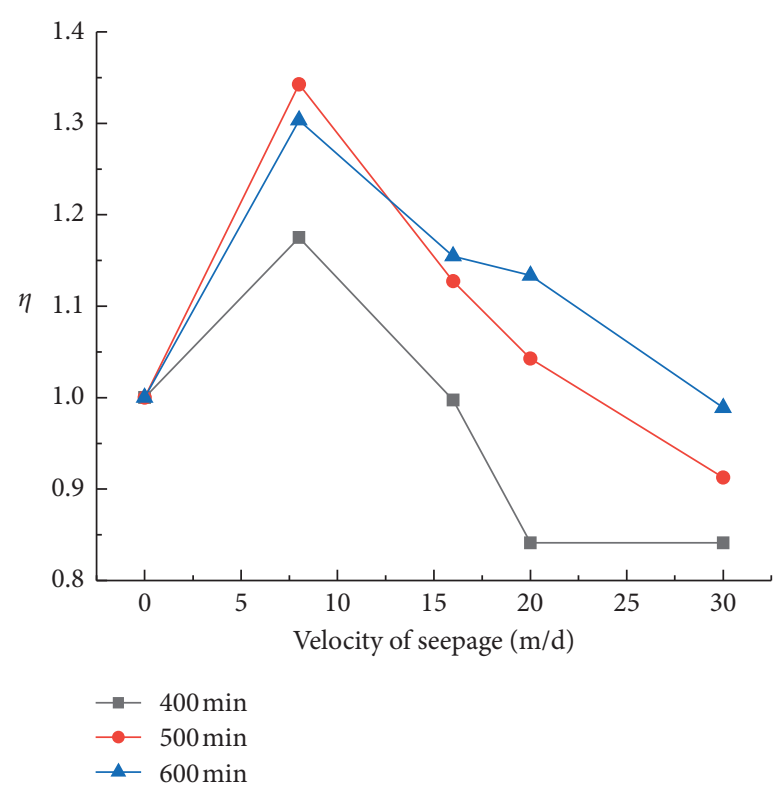

FIGURE 17: The relation curve between the damage coefficient and the seepage velocity.

seepage conditions can effectively reduce engineering treatment time and cost.

\section{Conclusion}

In this paper, the evolution laws of frozen wall formation under the influence of sudden seepage are analyzed through a series of model tests. The spatial-temporal variation characteristics of the thickness and average temperature of the frozen wall in relation to the flow field and the bearing capacity damage after the occurrence of seepage are analyzed. Based on the results, the following conclusions can be drawn:

(1) The frozen wall changed rapidly when seepage occurred. When the velocity of flow was not enough to destroy the frozen wall, a thin upstream and thick downstream eccentric frozen wall was formed. Moreover, the antiseepage properties of doublerowed pipes obviously outperformed those of the single-rowed pipes during freezing.

(2) According to the brine return temperature, the cold efficiency of all of the project's five tests was found to be consistent in the nonseepage stage. Following the start of seepage, brine return temperature increased rapidly.

(3) When the seepage velocity was $0 \sim 30 \mathrm{~m} / \mathrm{d}$, the seepage caused obvious damage to the upper reaches of the frozen wall, while the wall was strengthened in the middle and lower reaches to a small extent. When the flow velocity was more than $30 \mathrm{~m} / \mathrm{d}$, the frozen wall was completely damaged.

(4) After seepage occurred, the downstream frozen wall demonstrated a rapid expansion stage before the expansion rate of the frozen wall gradually approached a normal state. This stage was the most important stage for conversion from a symmetrically frozen wall to an eccentrically frozen wall. After the rapid expansion stage, the eccentrically frozen wall will take shape, and this time period thus presents the riskiest stage in the excavation process.

(5) After seepage occurred, the temperature field of the frozen wall indicated that the high-temperature permafrost area $\left(0 \sim-15^{\circ} \mathrm{C}\right)$ relatively reduced, while the low-temperature permafrost area $\left(-15 \sim-30^{\circ} \mathrm{C}\right)$ relatively increased. The average temperature of the frozen wall first increased and then decreased with the increase of the seepage velocity.

(6) Based on the analysis of the damage coefficient, it can be concluded that the bearing capacity of the frozen wall increases first and then decreases. At a seepage rate of $8 \mathrm{~m} / \mathrm{d}$, the bearing capacity of the frozen wall can thus be expected to increase significantly. It is proposed that if low-flow velocity seepage occurs during construction, it does not need to extend the freezing time.

\section{Data Availability}

The data used to support the findings of this study are included within the article.

\section{Conflicts of Interest}

The authors declare no conflicts of interest.

\section{Acknowledgments}

The scientific research program was supported by the State Key Laboratory of Mechanical Behavior and System Safety of Traffic Engineering Structures, Shijiazhuang Tiedao 
University (ZZ2020-07) and the Special Funds for Scientific and Technological Innovation of Tiandi Science \& Technology Co., Ltd. (2019-TD-QN009 and 2019-TD-MS007).

\section{References}

[1] M. A. Alzoubi, M. Xu, F. P. Hassani et al., "Artificial ground freezing: a review of thermal and hydraulic aspects," Tunnelling and Underground Space Technology, vol. 104, Article ID 103534, 2016.

[2] X.-D. Hu, T. Fang, and Y.-G. Han, "Mathematical solution of steady-state temperature field of circular frozen wall by singlecircle-piped freezing," Cold Regions Science and Technology, vol. 148, pp. 96-103, 2018.

[3] P. Erich, S. Anton, and G. Anagnostou, "Modelling of ground freezing in tunnelling," ITA and World Tunnel Congress, Prague, 2007.

[4] P. Erich, S. Anton, and G. Anagnostou, "Large-scale laboratory tests on artificial ground freezing under seepage-flow conditions," Geotechnique, vol. 3, no. 62, pp. 227-241, 2012.

[5] P. Erich, S. Papakonstantinou, and G. Anagnostou, "Numerical interpretation of temperature distributions from three ground freezing applications in urban tunnelling," Tunnelling and Underground Space Technology, vol. 28, pp. 57-69, 2012.

[6] M. Vitel, A. Rouabhi, M. Tijani, and F. Guérin, "Modeling heat and mass transfer during ground freezing subjected to high seepage velocities," Computers and Geotechnics, vol. 73, pp. 1-15, 2016.

[7] S. Huang, Y. Guo, Y. Liu, L. Ke, G. Liu, and C. chen, "Study on the influence of water flow on temperature around freeze pipes and its distribution optimization during artificial ground freezing," Applied Thermal Engineering, vol. 135, pp. 435-445, 2018.

[8] M. A. Alzoubi and A. P. Sasmito, "Development and validation of enthalpy-porosity method for artificial ground freezing under seepage conditions," Fluids Engineering Division Summer Meeting, vol. 51562, 2018.

[9] S. Zhang, Z. R. Yue, T. C. Sun et al., "Evolution of ground freezing temperature field under sudden seepage with stable flow rate and discriminate method of seepage," Journal of China Coal Society, vol. 51, 2018.

[10] R. L. Shan, J. W. Liu, G. J. Chai et al., "Experimental study on the expansion law of local horizontal frozen body under seepage," Journal of China Coal Society, vol. 44, pp. 526-534, 2019.

[11] W. J. Liu, J. J. Zhang, R. L. Shan et al., "Experiments on temperature field of multi-row-pipe partial horizontal freezing body in Beijing sand-gravel stratum under seepage," Rock and Soil Mechanics, vol. 44, no. 9, pp. 3425-3434, 2019.

[12] J. Y. Yu, "Coping with water gushing in shield arrival," Tunnel Construction, vol. 33, no. 4, pp. 315-318, 2013.

[13] F. Z. Li, F. R. Luo, Y. F. Han et al., "Cause analysis and countermeasure research for unclosed freezing wall of subway contact passage under complex conditions," Industrial Construction, vol. 45, no. 11, pp. 187-190, 2015.

[14] S. Ao, "Longitudinal temperature measuring Technology applied to ground freezing construction of Metro connecting passage," Mine Construction Technology, vol. 38, no. 3, pp. 54-58, 2017.

[15] H. Cai, S. Li, Z. Yao, and H. Cheng, "Model test and numerical simulation of frost heave during twin-tunnel construction using artificial ground-freezing technique," Computers and Geotechnics, vol. 115, 2019.
[16] J. Liu, B. Ma, and Y. Cheng, "Design of the Gongbei tunnel using a very large cross-section pipe-roof and soil freezing method," Tunnelling and Underground Space Technology, vol. 72, pp. 28-40, 2018.

[17] F. Z. Li, H. Ding, and X. Z. Zhang, "Model test research of formation law of double-row-pipe freezing wall in water rich sand layer under seepage," Chinese Journal of Rock Mechanics and Engineering, vol. 38, no. 2, pp. 386-395, 1975.

[18] S. B. Bai, H. Chen, and J. Wang, "An introduction to nine gridding methods and their application in surfer version 7.0," Computing Techniques for Geophysical and Geochemical Exploration, vol. 24, no. 2, pp. 157-163, 2002.

[19] F. Z. Li, "Application and prospect of freezing Technology in municipal engineering," Mine Construction Technology, vol. 38, no. 4, pp. 55-60, 2017.

[20] Y. Q. Zhang, P. Yang, and J. Y. Wang, "Effect of water content and strain rate on the strength characteristics of frozen silty clay," Journal of Zhengzhou University(Engineering Science), vol. 41, no. 3, pp. 79-84, 2020. 